Copyright (C 2012 IEEE. Personal use of this material is permitted. Permission from IEEE must be obtained for all other uses, in any current or future media, including reprinting/republishing this material for advertising or promotional purposes, creating new collective works, for resale or redistribution to servers or lists, or reuse of any copyrighted component of this work in other works. 


\title{
Characterization of Transformer FRA Signature under Various Winding Faults
}

\author{
Naser Hashemnia, A. Abu-Siada, Mohammad A.S. Masoum, and Syed M. Islam \\ Electrical and Computer Engineering Department, Curtin University, Western Australia \\ Corresponding Author: a.abusiada@curtin.edu.au
}

\begin{abstract}
Frequency response analysis (FRA) is gaining global popularity in detecting power transformer winding and core deformations due to the development of FRA test equipment. However, because FRA relies on graphical analysis, interpretation of its signatures is still a very specialized area that calls for skillful personnel to detect the sort and likely place of the fault as so far, there is no reliable standard code for FRA signature classification and quantification. This paper aims to initiate the establishment of standard codes for FRA signature interpretation through comprehensive simulation analysis on a detailed transformer distributed parameters-based model. Various mechanical faults such as axial displacement, buckling stress, disk space variation and bushing fault are simulated on the model to study its impact on the FRA signature. The main contribution of this paper is the comprehensive table it presents for FRA signature sensitivity to winding and core deformations that can be used for classification and quantification of the transformer FRA signature.
\end{abstract}

Index Terms: Power transformer, FRA, condition monitoring, core and winding deformation.

\section{INTRODUCTION}

$T_{i}$ HE majority of transformers currently in service were installed prior to 1980 and as a result the bulk of the population is approaching or has already exceeded its design life $[1,2]$. This poses a significant risk for utilities and other power network stakeholders as the impact of in service transformer failure can be catastrophic. The mechanical forces that a transformer is exposed to during faults, switching transients and other system events result in magnetic forces being imposed on the windings. If these forces exceed the withstand capability of the transformer, winding deformation may occur [3, 4]. One of the causes of transformer mechanical damages and windings deformation is the loss of clamping pressure because of insulation degradation resulted by ageing. While with only minor winding deformation transformer can still working normally, its capability to withstand any further through faults will gradually decrease [5]. Therefore, it is very essential to identify any minor winding deformation as soon as possible and take a proper asset management decision to avoid disastrous failures. Winding deformation has various configuration moods such as spiral tightening, conductor tilting, radial buckling and collapse of the winding end supports. It is hard to identify these types of internal faults with conventional testing methods [6] .One of the powerful diagnostic techniques in identifying internal faults of power transformers is the frequency response analysis (FRA) test [7]. Since power transformer components including windings, core and insulation can be represented by equivalent electrical parameters comprising resistors, capacitors, and self / mutual inductances, the value of these electrical parameters will be altered for any mechanical fault within the power transformer and hence the frequency response of the winding will change accordingly. FRA is an offline test that is conducted by injecting a sweep frequency, low voltage to one terminal of transformer winding and measuring the response across the other terminal of the winding with reference to the tank. The FRA response is the ratio between the magnitude of the response signal $V_{o}$ and the source voltage $V_{i}$ as a function of the frequency in decibel $(\mathrm{dB})$ [8]. The FRA signature is considered as a fingerprint of the transformer that can be compared with its previous signatures to identify any changes to the fingerprint and hence identifying any mechanical deformation. Transformers fingerprints however are rarely available, particularly for old transformers. In this case other comparison methods such as phase-to-phase comparison or comparing the signatures of sister transformers can be adopted. While the testing technique is quite simple because of the development of FRA test equipment, FRA signature interpretation is still a very specialized area that calls for skillful personnel to detect the sort and likely place of the fault. This is not always an easy task especially for young and inexperienced power engineers. This paper introduces an attempt to quantify and classify transformer FRA signatures using sensitivity analysis. Detailed simulation analysis is performed on a transformer distributed parameters model to investigate and to classify the impacts of internal faults on the FRA signature. Mechanical faults such as axial displacement, radial buckling, disk space variation, loss of clamping, bushing and leakage faults are emulated by appropriately modifying the transformer distributed parameters. Finally, a general interpretation code that can be readily used to classify FRA signatures is developed.

\section{TRANSFORMER MODEL}

Simplorer software is used to simulate the transformer model shown in Fig.1 [9]. In the model under study, the high voltage $(\mathrm{HV})$ and low voltage $(\mathrm{LV})$ windings are assumed to consist of 10 disks. Each disk comprises series resistance $\left(R_{S}\right)$ and inductance $\left(L_{s}\right)$ shunted by a capacitor $\left(C_{s h}\right)$ and a conductance $\left(G_{s h}\right)$. The capacitance between HV winding and $\mathrm{LV}$ winding $\left(C_{H L}\right)$ is shunted by dielectric conductance $\left(G_{H L}\right)$, also mutual inductances $\left(M_{i j}\right)$ between relevant coils are represented. The dielectric insulation between the LV winding and the earthed core and that is between the HV winding and the earthed tank are simulated by a capacitance $\left(C_{g}\right)$ and dielectric conductance $(G)$ as shown in Fig. 1. The physical meaning of the model parameters allows the identification of 
the problem inside the transformer and helps in establishing a standard code for FRA signature interpretation.

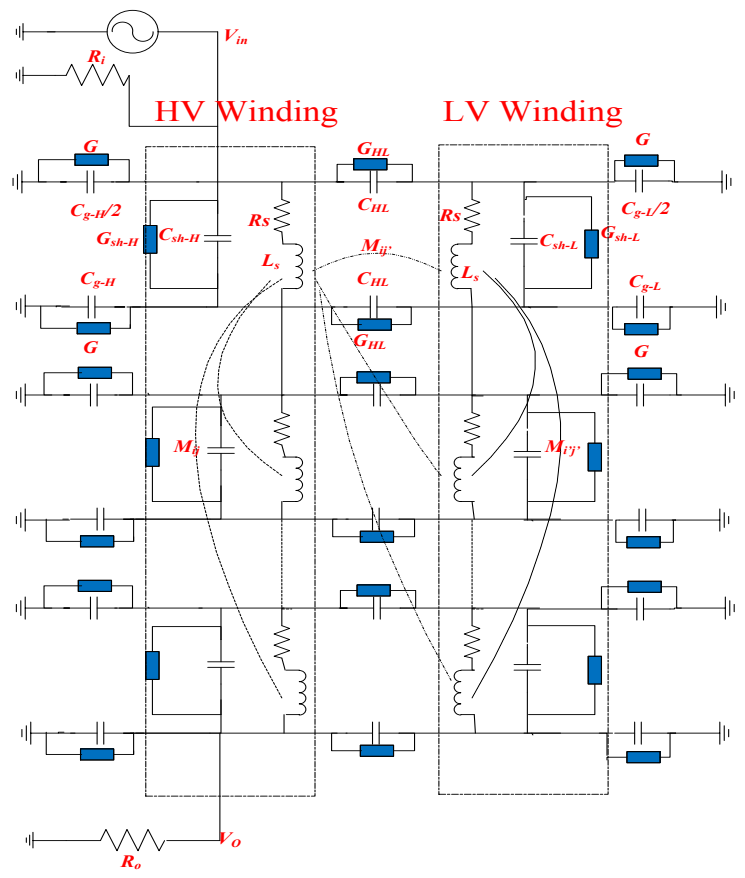

Fig. 1 Transformer distributed parameters model

\section{FAULT ANALYSIS}

In this section various mechanical faults are simulated within the transformer model by changing particular parameters. The faulty signature is compared with the healthy one in order to investigate the impact of each fault on the FRA signature.

\section{A. Loss of Clamping Pressure}

Losing clamping-pressure is a common problem particularly for aged transformers. This is caused by the mechanical hysteresis in pressboard and paper [10]. Loss of clamping causes an increase in oil conductivity because of the reduction in dielectric thickness between winding layers. This type of fault can be simulated by increasing the value of the shunt conductance $G_{s h}$ [11]. Figs. 2 and 3 show the effect of $20 \%$ loss of clamping pressure on the FRA signature for $\mathrm{HV}$ and LV windings. According to these two figures, this type of fault will not affect the location of resonance and anti-resonance frequencies. However, it significantly reduces the magnitude of maximum and minimum peaks in the mid and high frequency ranges.

\section{B. Inter Disk Fault}

The inter-disk fault is considered as one of the most common mechanical faults within power transformers. Studies show that around $80 \%$ of transformer breakdowns are due inter-disk fault [12]. This fault is due to axial disk space variation which is caused by the excess mechanical stress and through faults and can be simulated by increasing the series capacitance $\left(C_{s h}\right)$ and the mutual inductance between the two impacted disks [12]. Fig. 4 shows the impact of $10 \%$ of such fault on the HV FRA signature when occurs at different locations in the transformer model shown in Fig. 1.

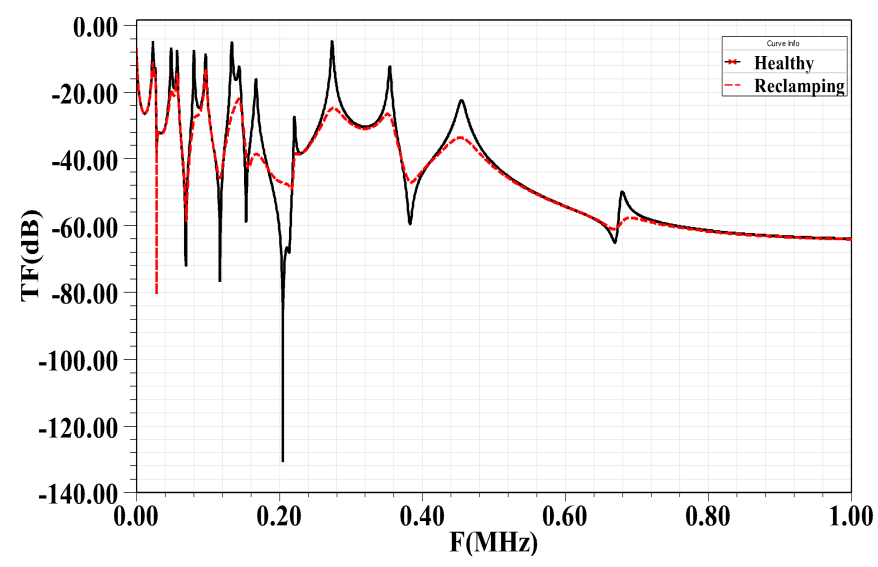

Fig. 2 Impact of clamping fault on the HV FRA signature

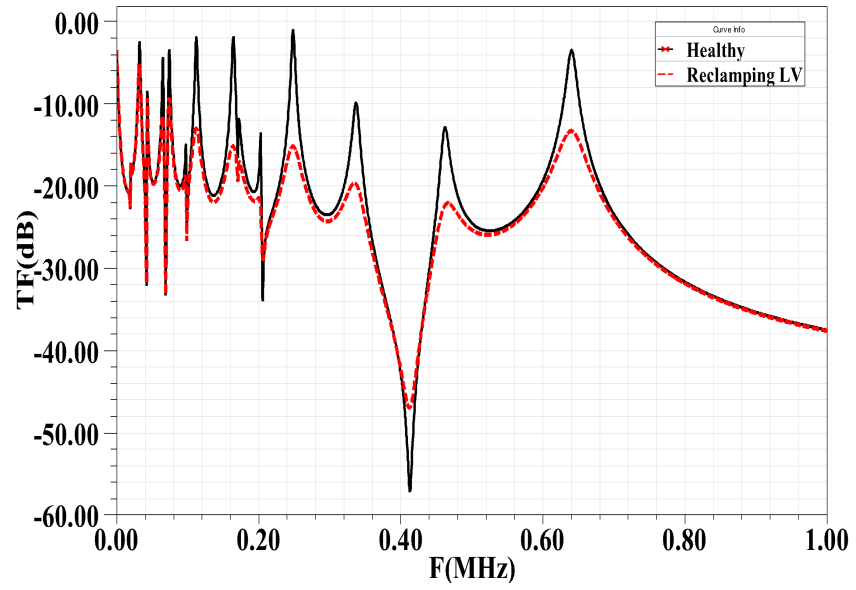

Fig. 3 Impact of clamping fault on the LV FRA signature

Fig. 4 shows that this fault has no signeficant impact on the signature in the low frequency range. A shift to the right in the resonance and anti-resonance frequencies can be observed after $100 \mathrm{kHz}$ with significant change in the peak magnitudes. The shifts in resonance and anti-resonance frequencies are more observable when the fault occurs at the top or bottom disks of the winding while the impact of this fault is less when occurs at the middle disks of the windings.

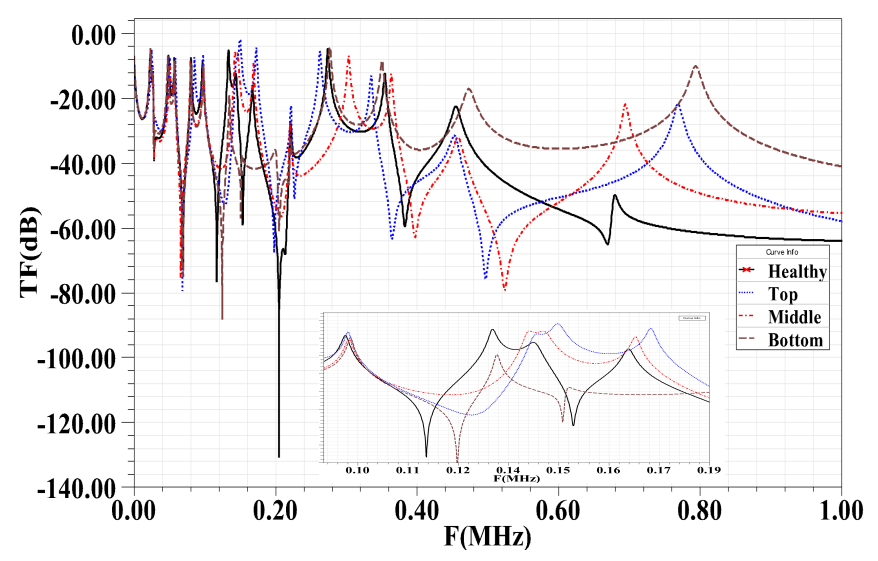

Fig. 4 Impact of inter-disk fault on the HV FRA signature

\section{High Voltage Bushing Fault}

Bushing can be simulated by adding a " $T$ " circuit model to the transformer model as shown in Fig. 5 [13]. The impact of 
$10 \%$ change in bushing capacitance on the FRA signature is shown in Fig. 6. The results reveal that there is no impact of this fault on the signature in the low and medium frequency range. However, a slight change in magnitude can be observed after $250 \mathrm{kHz}$ and the magnitude increases in the high frequency range but there is no change in the position of resonant peaks.

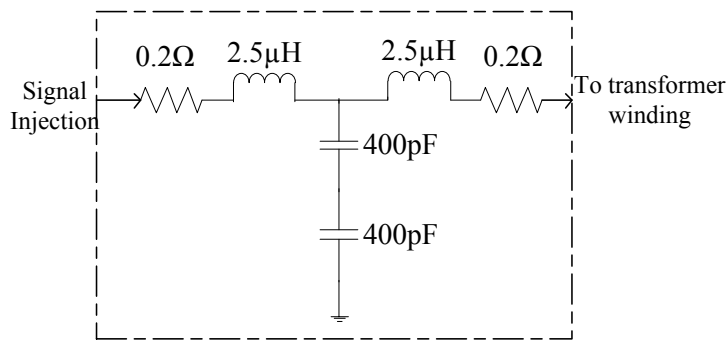

Fig. 5 Bushing model [13]

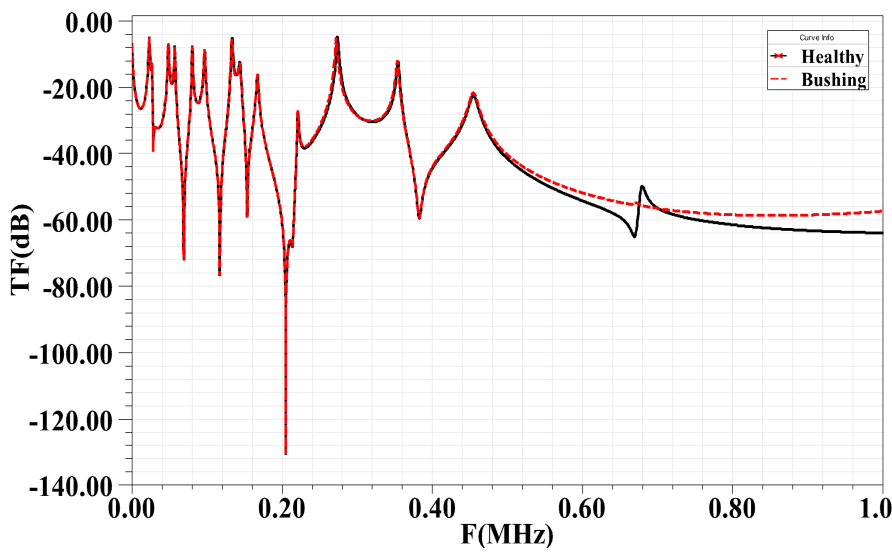

Fig. 6 Impact of high voltage bushing fault on the FRA signature

\section{Axial Displacement}

This fault occurs due to the imbalanced magnetic forces generated in one winding as a result of a short-circuit fault [11] which leads to the movement of the impacted winding axially. This fault can be simulated by changing the values of the series capacitance $\left(C_{s h}\right)$ and mutual inductance [14]. Fig. 7 shows the impact of $10 \%$ of such fault on the FRA signature of the HV winding when it is moved axially up or down. As shown in Fig. 7, this fault has no impact on the FRA signature in the low frequency range. However, after $200 \mathrm{kHz}$ a slight shift of anti-resonance frequencies to the right with observable increase in the magnitude can be detected. The trend is similar for both fault directions.

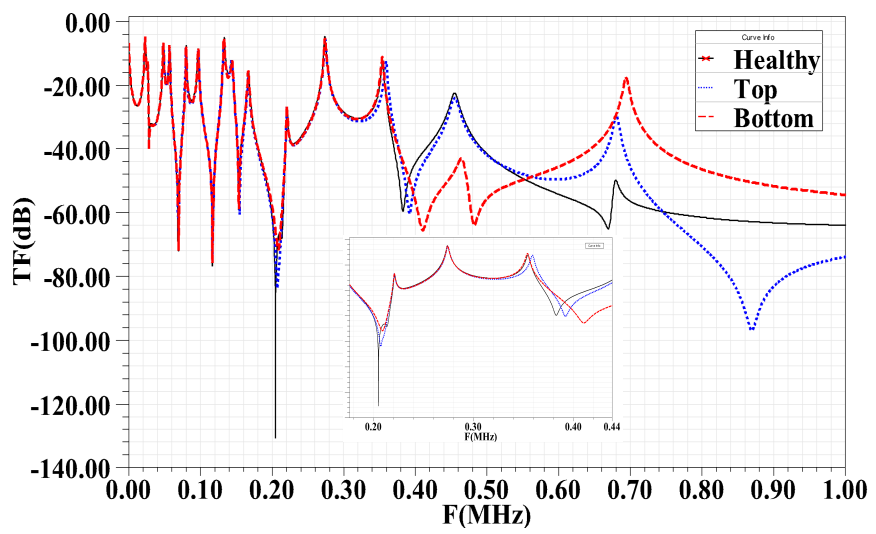

Fig. 7 Impact of HV axial dispalcment on the FRA signature

\section{E. Leackage Fault}

Ground shield damage, insulation damage, high moisture content in the winding, abrasion, hotspot and aging insulation, are the main causes for leakage fault within a power transformer [15]. This type of fault can be simulated by increasing the conductance to ground $(G)$ [16]. As can be observed from Fig. 8, there is no significant variation on the FRA signature. Althogh, a slight change in magnitude in the mid and high frequency range can be noticed.

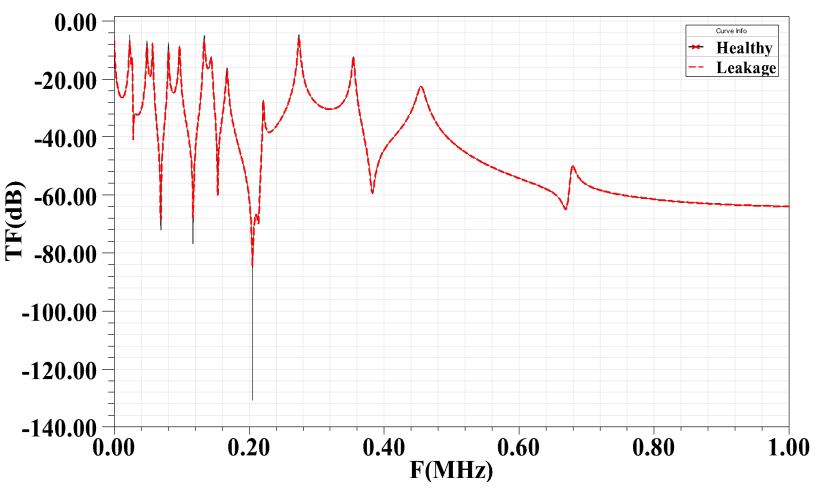

Fig. 8 Impact of leakage fault on the FRA signature

\section{F. Short Circuit Fault}

This fault is caused due to erosion of the winding and conductor insulation because of vibrations caused by the electromechanical forces that can lead to over current in the winding and sever dameges such as winding deformation, oil heating and even core damages may occur [17]. This fault can be simulated by short ciruting the series resistance and inductance [18]. Fig. 9 shows the impact of this fault on the FRA signature. It can be seen that the magnitude is significantly reduced at low frequency range. Different fault locations have a similar impact on the FRA signature.

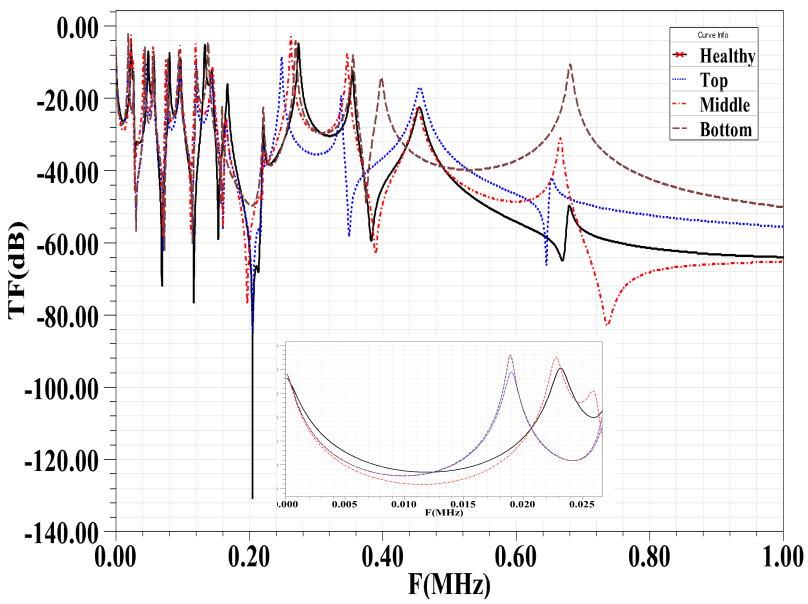

Fig. 9 Impact of HV short circuit fault on the FRA signature

\section{G. Radial Fault}

The windings of power transformers might be subjected to radial forces due to interactions of the winding current and magnetic flux. Significant amount of radial forces may lead to winding buckling [19]. This fault can be simulated by changing the capacitor to ground $\left(C_{g}\right)$ and the capacitor between the $\mathrm{HV}$ and $\mathrm{LV}$ windings $\left(C_{H L}\right)$ along with the mutual 
inductance of the impacted disks $\left(M_{i j}\right)$ [20]. 10\% of this fault is simulated at three different locations on the $\mathrm{HV}$ windings (top, middle and bottom) and the FRA response is shown in Figs. 10, which reveals that resonance frequencies are shifted to the right in the entire frequency range due to this type of fault. Also, the magnitude is increasing in the high frequency range. The trend for the three studied fault locations is quite the same.

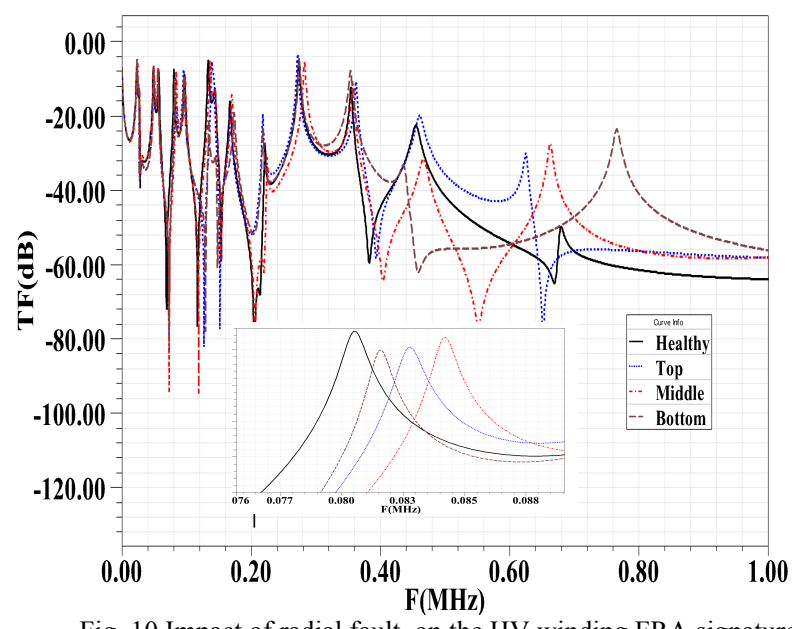

Fig. 10 Impact of radial fault on the HV winding FRA signature

TABLE I

SUMMARY OF VARIOUS FAULTS ON TRANSFORMER FRA SIGNATURE

\begin{tabular}{|c|c|c|c|}
\hline \multirow{2}{*}{$\begin{array}{l}\text { Fault } \\
\text { Type }\end{array}$} & \multicolumn{3}{|c|}{ Frequency Range } \\
\hline & Low & Medium & High \\
\hline Axial & $\begin{array}{c}\text { Magnitude } \\
\text { decreased slightly }\end{array}$ & $\begin{array}{l}\text { Anti resonates } \\
\text { shifted to right }\end{array}$ & $\begin{array}{c}\text { Magnitude } \\
\text { increased and } \\
\text { resonate peaks } \\
\text { shifted to right }\end{array}$ \\
\hline $\begin{array}{l}\text { Radial } \\
\text { HV \& LV }\end{array}$ & $\begin{array}{l}\text { Resonant peaks } \\
\text { shifted to right } \\
\text { slightly }\end{array}$ & $\begin{array}{c}\text { Resonant peaks } \\
\text { shifted to right }\end{array}$ & $\begin{array}{c}\text { Magnitude } \\
\text { increased and } \\
\text { resonant peaks } \\
\text { shifted to right }\end{array}$ \\
\hline Bushing & $\begin{array}{l}\text { Magnitude } \\
\text { increased } \\
\text { slightly }\end{array}$ & $\begin{array}{l}\text { Magnitude } \\
\text { increased } \\
\text { slightly }\end{array}$ & $\begin{array}{l}\text { Magnitude } \\
\text { increased } \\
\text { significantly }\end{array}$ \\
\hline Leakage & $\begin{array}{l}\text { Magnitude } \\
\text { decreased }\end{array}$ & $\begin{array}{l}\text { Magnitude } \\
\text { decreased }\end{array}$ & $\begin{array}{l}\text { Magnitude } \\
\text { decreased }\end{array}$ \\
\hline $\begin{array}{l}\text { Inter } \\
\text { Disk }\end{array}$ & $\begin{array}{l}\text { Magnitude } \\
\text { decreased }\end{array}$ & $\begin{array}{c}\text { Anti resonates } \\
\text { shifted to right } \\
\text { and magnitude } \\
\text { increased }\end{array}$ & $\begin{array}{c}\text { Magnitude } \\
\text { increased and } \\
\text { resonant peaks } \\
\text { shifted to right }\end{array}$ \\
\hline $\begin{array}{l}\text { Short } \\
\text { Circuit }\end{array}$ & $\begin{array}{c}\text { Magnitude } \\
\text { decreased sharply } \\
\text { and resonant peaks } \\
\text { shifted to left }\end{array}$ & $\begin{array}{c}\text { Resonant peaks } \\
\text { shifted to left } \\
\text { magnitude } \\
\text { increased }\end{array}$ & $\begin{array}{c}\text { Magnitude } \\
\text { increased and } \\
\text { resonate peaks } \\
\text { shifted to left }\end{array}$ \\
\hline $\begin{array}{l}\text { Clamping } \\
\text { HV\& LV }\end{array}$ & $\begin{array}{l}\text { Magnitude } \\
\text { decreased }\end{array}$ & $\begin{array}{l}\text { Magnitude } \\
\text { decreased }\end{array}$ & $\begin{array}{l}\text { Magnitude } \\
\text { decreased }\end{array}$ \\
\hline
\end{tabular}

Table I summarise the the impact of individual faults on the transformer FRA signature and be used as a step toward the establishment of standard codes for power transformer FRA signature interpretation.

\section{CONCLUSION}

This paper presents a comperhensive simulation analysis to explore the impact of various transformer mechanical faults on its frequency response analysis (FRA) signature. Results show that the effects of axial and radial faults are more observable at the medium to high frequency ranges and they are affecting the location of anti-resonances and resonance peaks. Short circuit fault can be detected at low frequency range as it will change the magnitude of the FRA signature. Inter-disk fault is clearly detectable at medium frequency range. Leakage fault and high voltage bushing fault affect the magnitude at the high frequency range and they have insignificant impact on the position of resonance and anti-resonance peaks. A comprehensive table highlighting transformer FRA sensitivities to mechanical faults is generated and can be used to establish standard codes for power transformer FRA signature interpretation.

\section{REFERENCES}

[1] S. M. Islam, K. M. Coates, and G. Ledwich, "Identification of high frequency transformer equivalent circuit using Matlab from frequency domain data," in Industry Applications Conference, 1997. Thirty-Second IAS Annual Meeting, IAS '97., Conference Record of the 1997 IEEE, 1997, pp. 357-364 vol.1.

[2] E. J. Figueroa, "Managing An Aging Fleet of Transformers," Canada, 2009.

[3] L. M. Geldenhuis, "Power transformer life management," in Electricity Distribution, 2005. CIRED 2005. 18th International Conference and Exhibition on, 2005, pp. 1-4.

[4] S. M. Islam and G. Ledwich, "Locating transformer faults through sensitivity analysis of high frequency modeling using transfer function approach," in Electrical Insulation, 1996., Conference Record of the 1996 IEEE International Symposium on, 1996, pp. 38-41 vol.1.

[5] E. Rahimpour, M. Jabbari, and S. Tenbohlen, "Mathematical comparison methods to assess transfer functions of transformers to detect different types of mechanical faults," Power Delivery, IEEE Transactions on, vol. 25, pp. 2544$2555,2010$.

[6] B. J. Small and A. Abu-Siada, "A new method for analysing transformer condition using frequency response analysis," in Power and Energy Society General Meeting, 2011 IEEE, 2011, pp. 1-5.

[7] S. D. Mitchell and J. S. Welsh, "Modeling power transformers to support the interpretation of frequency-response analysis," Power Delivery, IEEE Transactions on, vol. 26, pp. 2705-2717, 2011.

[8] E. Rahimpour, J. Christian, K. Feser, and H. Mohseni, "Transfer function method to diagnose axial displacement and radial deformation of transformer winding," Power Engineering Review, IEEE, vol. 22, pp. 70-70, 2002.

[9] L. Satish and S. K. Sahoo, "An effort to understand what factors affect the transfer function of a two-winding transformer," Power Delivery, IEEE Transactions on, vol. 20, pp. 1430-1440, 2005.

[10] G. Junfeng, G. Wensheng, T. Kexiong, and G. Shengyou, "Deformation analysis of transformer winding by structure parameter," in Properties and Applications of Dielectric Materials, 2003. Proceedings of the 7th International Conference on, 2003, pp. 487-490 vol.1.

[11] A. Abu-Siada and S. Islam, "A novel online technique to detect power transformer winding faults," Power Delivery, IEEE Transactions on, vol. PP, pp. 1-1, 2012.

[12] E. Rahimpour and S. Tenbohlen, "Experimental and theoretical investigation of disc space variation in real high-voltage windings using transfer function method," Electric Power Applications, IET, vol. 4, pp. 451-461, 2010.

[13] M. Wang, A. J. Vandermaar, and K. D. Srivastava, "Improved detection of power transformer winding movement by extending the FRA high frequency range," Power Delivery, IEEE Transactions on, vol. 20, pp. 1930-1938, 2005.

[14] V. Behjat and A. Vahedi, "Numerical modelling of transformers interturn faults and characterising the faulty transformer behaviour under various faults and operating conditions," Electric Power Applications, IET, vol. 5, pp. 415431, 2011.

[15] N. Abeywickrama, Y. V. Serdyuk, and S. M. Gubanski, "Effect of core magnetization on frequency response analysis (FRA) of power transformers," Power Delivery, IEEE Transactions on, vol. 23,pp. 1432-1438, 2008.

[16] J. Chong and A. Abu-Siada, "A novel algorithm to detect internal transformer faults," in Power and Energy Society General Meeting, 2011 IEEE, 2011.

[17] M.R.Barzegaran, "Detecting the position of winding short circuit faults in transformer using high frequency analysis," European Journal of Scientific Research ISSN 1450-216X Vol.23 No.4 (2008), pp.644-658, 2008

[18] J. Bak-Jensen, B. Bak-Jensen, and S. D. Mikkelsen, "Detection of faults and ageing phenomena in transformers by transfer functions," Power Delivery, IEEE Transactions on, vol. 10, pp. 308-314, 1995.

[19] K. Pourhossein, G. B. Gharehpetian, and E. Rahimpour, "Buckling severity diagnosis in power transformer windings using Euclidean Distance classifier," in Electrical Engineering (ICEE), 2011 19th Iranian Conference on, 2011.

[20] W. H. Tang, A. Shintemirov, and Q. H. Wu, "Detection of minor winding deformation fault in high frequency range for power transformer," in Power and Energy Society General Meeting, 2010 IEEE, 2010, pp. 1-6. 